\title{
DYNAMIC VENDOR SELECTION: A FUZZY AHP APPROACH
}

\author{
Saroj Koul \\ School of Business \\ Acadia University \\ Wolfville, NS, CANADA \\ Email: saroj.koul@acadiau.ca \\ Rakesh Verma \\ Operations Management Group \\ National Institute of Industrial Engineering (NITIE) \\ Mumbai, INDIA \\ Email: rverma01@ rediffmail.com
}

\begin{abstract}
In the ever-changing business world, appropriate vendor selection can be crucial in supply chain management. Dynamic models supporting vendors with time axis are not always crisp; rather they involve a high degree of fuzziness and uncertainty in real life situations. This paper proposes a dynamic model with uncertainty based on Fuzzy AHP for long-term strategic vendor selection problems. The selection of partnership suppliers is likewise illustrated by this methodology.
\end{abstract}

Key words: Analytic hierarchy process (AHP), Dynamic model, Fuzzy Sets, Supply Chain Management

\section{Introduction}

In today's highly competitive and interrelated manufacturing environment, materials represent a substantial part of the value of products. In view of the high percentage of the material cost, the key objective of the purchasing department ought to be purchasing the right quality of a product in the right quantity from the right source at the right time. The right source can provide the right quality of material on time at a reasonable price (Heizer and Render, 2001).

Supplier evaluation and selection are very important to the success of a manufacturing firm because the cost and quality of goods and services sold are directly related to the cost and quality of goods and services purchased. Therefore, purchasing and supplier selection have an important role in the supply chain process (Hartley and Choi, 1996; Degraeve, Labro, and Roodhooft, 2000). Traditionally, vendors are selected on their ability to meet the quality requirements, delivery schedule, and the price offered. The problem of finding and evaluating the most suitable vendor(s) usually emerges when the purchase is complex, high-dollar value, and perhaps critical. A process of formal vendor evaluation and ranking is also necessary. The process for vendor selection is indeed a problem-solving process, which covers the work of problem definition, formulation of criteria, qualification, and choice.

The supplier selection process is a multi-objective decision, encompassing many tangible and intangible factors in a hierarchical manner. Traditional methodologies of the supplier selection process in research literature include the cost-ratio method, the categorical method, weighted-point evaluations, mathematical programming models and statistical or probabilistic approaches (Yan, Yu, and Cheng, 2003; Oliveria and Vadi, 2002). Dickson has identified 23 important criteria in the study of supplier decision-making (Dickson, 1966). Weber et al.(2000) have compiled many articles in this area and used a linear weighting model for supplier selection. Linear weighting models place a weight on each criterion and provide a total score for each supplier by summing up the supplier's performance on the criteria multiplied by these 
weights. Hokey Min used a multi-attribute utility approach in international supplier selection (Min, 1994). Using interpretative structural modeling in their study, Mandal and Desmukh (1994) developed an analytical framework, which combines qualitative and quantitative factors. Youssef et al. (1996) developed a simple model for supplier evaluation and selection in an advanced manufacturing technology environment. Motwani et al. (1999) developed a model for the supplier selection process in developing countries. Drawbacks of these approaches include neglect of multi-period planning horizons for vendor selection, and selection of vendors based on experience and intuition. To overcome these problems, we use fuzzy analytic hierarchy process to propose the decision model.

\section{Dynamic Fuzzy AHP Method}

Competitive advantage is often determined by the effectiveness of an organization's supply chain, and as a result, the evaluation and selection of suppliers has become an increasingly important management activity. But the evaluation process is complex. Much of the data are difficult to obtain and ambiguous or vague to interpret. In addition, the dynamic global environment of changing exchange rates, economic conditions, and technical infrastructure, demand that the pool of potential suppliers be re-evaluated periodically.

The Analytic Hierarchy Process (AHP) is a powerful and flexible decision-making process (Saaty, 1980) to help managers set priorities and make the best decision when both qualitative and quantitative aspects of a decision need to be considered. By reducing complex decisions to a series of one-on-one comparisons, then synthesizing the results, many researchers have concluded that AHP is a useful, practical and systematic method for vendor rating (Barbarosoglu and Yazgac, 1997); it has certainly, been applied successfully. However, in many practical cases the human preference model is uncertain and decision-makers might be reluctant or unable to assign exact numerical values to the comparison judgments. For instance, when evaluating different suppliers, the decision-makers are usually unsure about their level of preference due to incomplete and uncertain information about possible suppliers and their performances. Since some of the supplier evaluation criteria are subjective and qualitative, it is very difficult for the decision-maker to express the strength of his preferences and to provide exact pair-wise comparison judgments. For this reason, a methodology based on fuzzy AHP can help us to reach an effective decision (Bellman and Zadeh, 1970). By this way we can deal with the uncertainty and vagueness in the decision process.

Fuzzy AHP consists of deriving the local priorities from these fuzzy preference ratios, which are subsequently aggregated to form the global priorities. The fuzzy AHP computes fuzzy priorities based on arithmetic operations for fuzzy triangular (or trapezoidal) numbers. To be able to use the fuzzy arithmetic operations, specific assumptions on the forms of membership functions are required. However, the most important criticism directed at fuzzy arithmetic operations is their failure to address the issue of consistency. There is no explicit articulation on what would constitute an inconsistent comparison matrix within the fuzzy AHP context and, equally important, on how inconsistent information should be handled. Lacking a mechanism to exclude inconsistent data, fuzzy priorities so obtained are likely to be flawed (Zimmerman, 1991; Buckley, Feuring, and Hayashi, 2001). In addition to combining the AHP approach with other methods, Zaim et al. (2003) has discussed fuzzy analytic hierarchy based approach for supplier selection in the area of marketing. Chan and Kumar (2007) extended it by including risk factors involved in global supplier selection to handle the fuzziness of the data involved in deciding the preferences of different decision variables. Chen et al. (2006) also employed a hierarchical model using triangular fuzzy numbers to deal with supplier selection problems. Benyoucef and Mustafa (2007) validated the design of the supplier selection system for a hospital and its underlying fuzzy AHP model.

In this study, the framework of feasible regions of relative weights was adopted. Firstly, allowing the feasible region to include tolerance deviations of the fuzzy ratios, we define fuzzy consistency as the 
existence of relative weights within the region. Secondly, we devise a maximum/minimum set ranking method to derive a crisp ranking from the global fuzzy weights (Noci and Toletti, 2000; Leung and Cao, 2000). The following steps of Fuzzy AHP proposed by Chang (1996) have been utilized selecting vendors in the multi-period phase.

According to the method of Chang's extent analysis, each object is taken and extent analysis for each goal is performed respectively. Therefore, $m$ extent analysis values for each object can be obtained, with the following signs:

$$
M_{g^{i}}^{1}, M_{g^{i}}^{2}, \ldots, M_{g^{i}}^{m}, i=1,2, \ldots, n .
$$

where $M_{g^{i}}^{j}(j=1,2, \ldots, m$. $)$ all are TFNs. The steps of Chang's extent analysis (Chang, 1996) can be given as in the following:

Step 1: The value of fuzzy synthetic extent with respect to the $i t h$ object is defined as

$$
S_{i}=\sum_{j=1}^{m} M_{g^{i}}^{j} \otimes\left[\sum_{i=1}^{n} \sum_{j=1}^{m} M_{g^{i}}^{j}\right]^{-1}
$$

To obtain $\sum_{j=1}^{m} M_{g^{i}}^{j}$, the fuzzy addition operation of $\mathrm{m}$ extent analysis values for a particular matrix is performed such as

$$
\sum_{j=1}^{m} M_{g^{i}}^{j}=\left(\sum_{j=1}^{m} l_{j}, \sum_{j=1}^{m} m_{j}, \sum_{j=1}^{m} u_{j}\right)
$$

and to obtain $\left[\sum_{i=1}^{n} \sum_{j=1}^{m} M_{g^{i}}^{j}\right]$, by performing the fuzzy addition operation of $M_{g^{i}}^{j} \quad(j=1,2, \ldots, m$. $)$ such that

$$
\left[\sum_{i=1}^{n} \sum_{j=1}^{m} M_{g^{i}}^{j}\right]=\left(\sum_{i=1}^{n} l_{i}, \sum_{i=1}^{n} m_{i}, \sum_{i=1}^{n} u_{i}\right)
$$

and $\left[\sum_{i=1}^{n} \sum_{j=1}^{m} M_{g^{i}}^{j}\right]^{-1}$ can be calculated by the inverse of Eq. (3), as follows:

$$
\left[\sum_{i=1}^{n} \sum_{j=1}^{m} M_{g^{i}}^{j}\right]^{-1}=\left(\frac{1}{\sum_{i=1}^{n} u_{i}}, \frac{1}{\sum_{i=1}^{n} m_{i}}, \frac{1}{\sum_{i=1}^{n} l_{i}}\right)
$$

Step 2: As $M_{1}=\left(l_{1}, m_{1}, u_{1}\right)$ and $M_{2}=\left(l_{2}, m_{2}, u_{2}\right)$ are two triangular fuzzy numbers, the degree of possibility of $M_{2}=\left(l_{2}, m_{2}, u_{2}\right) \geq M_{1}=\left(l_{1}, m_{1}, u_{1}\right)$ is defined as

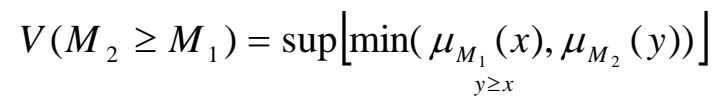


and can be expressed as follows:

$$
\begin{aligned}
& V\left(M_{2} \geq M_{1}\right)=\operatorname{hgt}\left(M_{1} \cap M_{2}\right)=\mu_{M_{2}}(d) \\
& =\left\{\begin{array}{cc}
1 & \text { if } m_{2} \geq m_{1} \\
0 & \text { if } l_{1} \geq u_{2} \\
\frac{\left(l_{1}-u_{2}\right)}{\left(m_{2}-u_{2}\right)-\left(m_{1}-l_{1}\right)} \text { otherwise }
\end{array}\right.
\end{aligned}
$$

Figure 1 illustrates Eq. (6) where $d$ is the ordinate of the highest intersection point D between $\mu_{M_{1}}$ and $\mu_{M_{2}}$. To compare $M_{1}=\left(l_{1}, m_{1}, u_{1}\right)$ and $M_{2}=\left(l_{2}, m_{2}, u_{2}\right)$, we need both the values of $V\left(M_{1} \geq M_{2}\right)$ and $V\left(M_{2} \geq M_{1}\right)$.

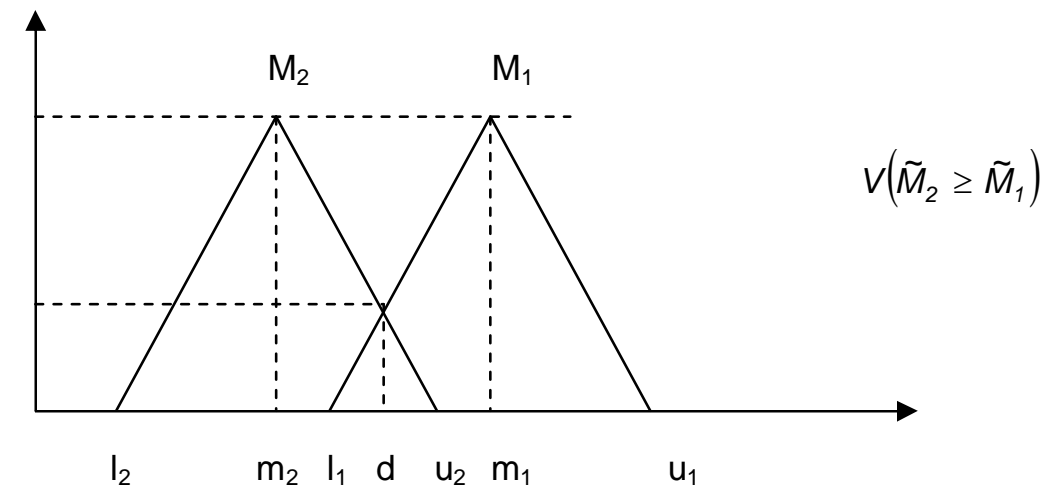

Figure 1: Intersection between $M_{1}$ and $M_{2}$ (Kahraman et al., 2004)

Step 3: The degree possibility for a convex fuzzy number to be greater than $k$ convex fuzzy $M_{i}(i=1,2, \ldots, k)$ numbers can be defined by

$$
\begin{aligned}
V\left(M \geq M_{1}, M_{2}, \ldots, M_{k}\right)=V[(M & \left.\left.\geq M_{1}\right) \text { and }\left(M \geq M_{2}\right) \text { and } \ldots \text { and }\left(M \geq M_{k}\right)\right] \\
& =\min V\left(M \geq M_{i}\right), i=1,2, \ldots, k
\end{aligned}
$$

Assume that

$$
d\left(A_{i}\right)=\min V\left(S_{i} \geq S_{k}\right) \text { for } k=1,2, \ldots, n ; k \neq i .
$$

Then the weight vector is given by

$$
W^{\prime}=\left(d^{\prime}\left(A_{1}\right), d^{\prime}\left(A_{2}\right), \ldots, d^{\prime}\left(A_{n}\right)\right)^{T}
$$

where $A_{i}(i=1,2, \ldots, n)$ are the $n$ elements. 
Step 4: Via normalization, the normalized weight vectors are

$$
W=\left(d\left(A_{1}\right), d\left(A_{2}\right), \ldots, d\left(A_{n}\right)\right)^{T}
$$

where $W$ is a non-fuzzy number.

\section{An Illustrative Example}

This numerical example presents a mathematical model to select suppliers in a multi-period environment.

\subsection{Define the criteria for vendor selection}

The main objective is the selection of the best supplier for a firm in a dynamic environment. The problem has three levels of hierarchy in kth period (where $\mathrm{k}=1,2,3)$. The analytic time periods are the past $(k=1)$, now $(k=2)$, and near future $(k=3)$. Thus, the decision makers can estimate the relative weights — ratios for each pair of alternatives under every attribute as well as the relative weights ratios for the attributes. Application of common criteria to all suppliers makes objectives comparisons possible. The criteria considered here in selection of the best supplier in a dynamic environment are:

- Quality of the product

- Delivery

- Overall cost of the product

- Flexibility in service

The hierarchy of the selection criteria and decision alternatives (i.e., suppliers) in dynamic environment can be seen in Figure 2. In the hierarchy, the overall objective (i.e., the best supplier) is placed at level 1, criteria at level 2, and the suppliers alternatives at level 3 in kth period (where $\mathrm{k}=1,2,3$ ).

The above mentioned criteria help in deciding the best supplier for an organization in each of the multiperiod phase. The preferences of one over other have been decided by the decision makers. The human judgment may not always be crisp and hence the evaluation scale, used by decision makers, is illustrated in Table 1.

\section{Table 1: FAHP scale}

\begin{tabular}{|l|l|}
\hline Definition & Intensity of importance \\
\hline Equal & $(1,1,1)$ \\
Weak & $(2 / 3,1,3 / 2)$ \\
Fairly strong & $(3 / 2,2,5 / 2)$ \\
Very strong & $(5 / 2,3,7 / 2)$ \\
Absolute & $(7 / 2,4,9 / 2)$ \\
\hline
\end{tabular}




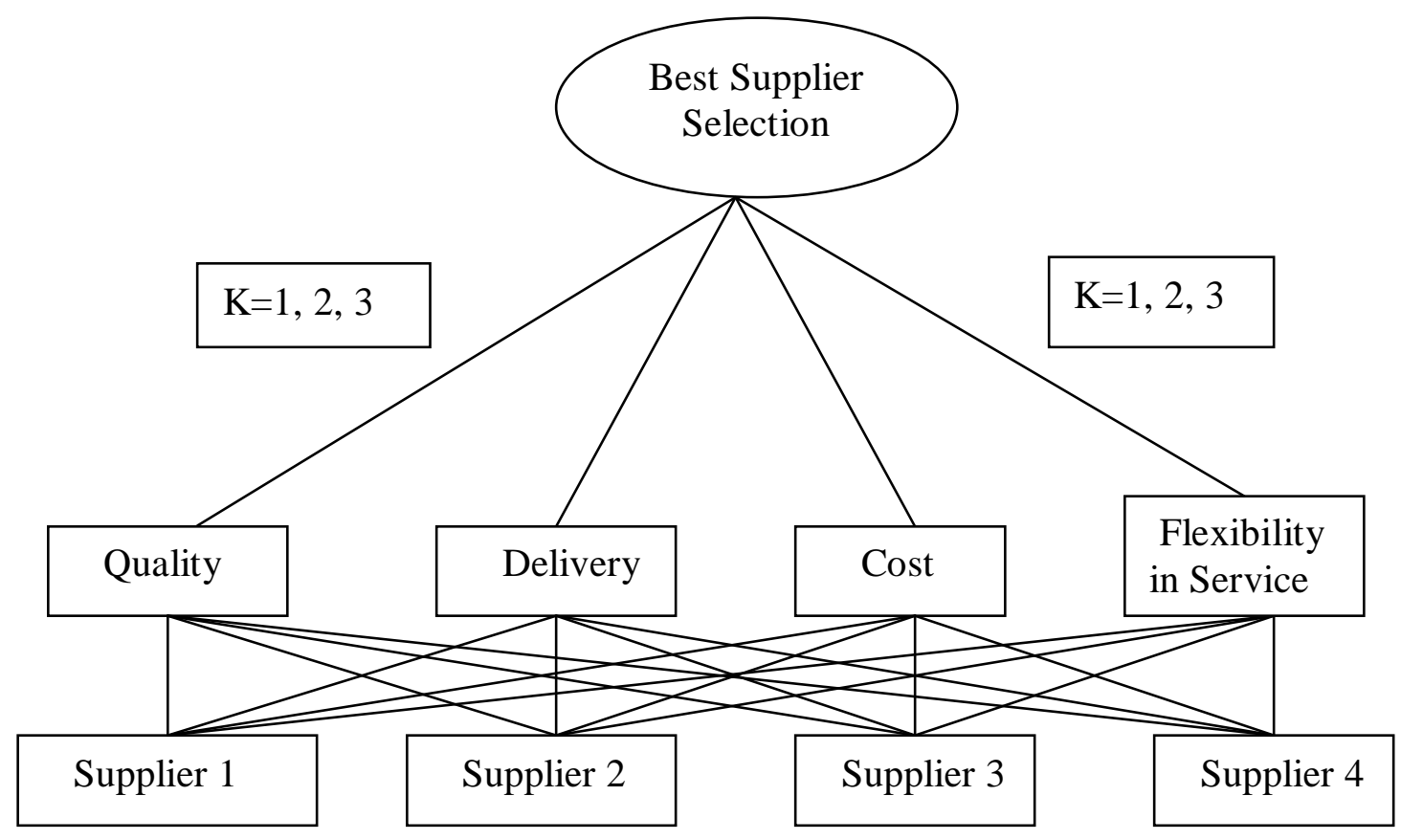

Figure 2: Dynamic Hierarchy for supplier selection

The fuzzy pair wise reciprocal judgments matrix by the decision maker for each criterion, with respect to overall objective (i.e., selecting the best supplier; (see Table 2), and for each supplier with each of the criterion (see Tables 3-6), are determined in each of the three periods by the help of FAHP scale defined in Table 1.

Table 2: The Criterion fuzzy pair wise comparison matrix in $k$ th period $(k=1,2,3)$

\begin{tabular}{|l|l|l|l|l|}
\hline & Quality & Delivery & Cost & $\begin{array}{l}\text { Flexibility } \\
\text { In Service }\end{array}$ \\
\hline Quality & $(1,1,1)$ & $(2 / 3,1,3 / 2)$ & $(3 / 2,2,5 / 2)$ & $(3 / 2,2,5 / 2)$ \\
& $(1,1,1)$ & $(5 / 2,3,7 / 2)$ & $(3 / 2,2,5 / 2)$ & $(3 / 2,2,5 / 2)$ \\
& $(1,1,1)$ & $(3 / 2,2,5 / 2)$ & $(5 / 2,3,7 / 2)$ & $(7 / 2,4,9 / 2)$ \\
\hline Delivery & $(2 / 3,1,3 / 2)$ & $(1,1,1)$ & $(2 / 5,1 / 2,2 / 3)$ & $(2 / 3,1,3 / 2)$ \\
& $(2 / 7,1 / 3,2 / 5)$ & $(1,1,1)$ & $(2 / 5,1 / 2,2 / 3)$ & $(2 / 3,1,3 / 2)$ \\
& $(2 / 5,1 / 2,2 / 3)$ & $(1,1,1)$ & $(5 / 2,3,7 / 2)$ & $(5 / 2,3,7 / 2)$ \\
\hline Cost & $(2 / 5,1 / 2,2 / 3)$ & $(3 / 2,2,5 / 2)$ & $(1,1,1)$ & $(1,1,1)$ \\
& $(2 / 5,1 / 2,2 / 3)$ & $(3 / 2,2,5 / 2)$ & $(1,1,1)$ & $(3 / 2,2,5 / 2)$ \\
& $(2 / 7,1 / 3,2 / 5)$ & $(2 / 7,1 / 3,2 / 5)$ & $(1,1,1)$ & $(3 / 2,2,5 / 2)$ \\
\hline Flexibility in & $(2 / 5,1 / 2,2 / 3)$ & $(2 / 3,1,3 / 2)$ & $(1,1,1)$ & $(1,1,1)$ \\
Service & $(2 / 5,1 / 2,2 / 3)$ & $(2 / 3,1,3 / 2)$ & $(2 / 5,1 / 2,2 / 3)$ & $(1,1,1)$ \\
& $(2 / 9,1 / 4,2 / 7)$ & $(2 / 7,1 / 3,2 / 5)$ & $(2 / 5,1 / 2,2 / 3)$ & $(1,1,1)$ \\
\hline
\end{tabular}


Table 3: The alternatives fuzzy pair wise comparison matrix with respect to criteria Quality in kth period $(k=1,2,3)$

\begin{tabular}{|l|l|l|l|l|}
\hline Quality & Supplier 1 & Supplier 2 & Supplier 3 & Supplier 4 \\
\hline Supplier 1 & $(1,1,1)$ & $(3 / 2,2,5 / 2)$ & $(3 / 2,2,5 / 2)$ & $(7 / 2,4,9 / 2)$ \\
& $(1,1,1)$ & $(2 / 5,1 / 2,2 / 3)$ & $(5 / 2,3,7 / 2)$ & $(3 / 2,2,5 / 2)$ \\
& $(1,1,1)$ & $(2 / 3,1,3 / 2)$ & $(3 / 2,2,5 / 2)$ & $(3 / 2,2,5 / 2)$ \\
\hline Supplier 2 & $(2 / 5,1 / 2,2 / 3)$ & $(1,1,1)$ & $(2 / 5,1 / 2,2 / 3)$ & $(3 / 2,2,5 / 2)$ \\
& $(3 / 2,2,5 / 2)$ & $(1,1,1)$ & $(2 / 5,1 / 2,2 / 3)$ & $(2 / 3,1,3 / 2)$ \\
& $(2 / 3,1,3 / 2)$ & $(1,1,1)$ & $(2 / 5,1 / 2,2 / 3)$ & $(2 / 3,1,3 / 2)$ \\
\hline Supplier 3 & $(2 / 5,1 / 2,2 / 3)$ & $(2 / 7,1 / 3,2 / 5)$ & $(1,1,1)$ & $(3 / 2,2,5 / 2)$ \\
& $(2 / 7,1 / 3,2 / 5)$ & $(3 / 2,2,5 / 2)$ & $(1,1,1)$ & $(3 / 2,2,5 / 2)$ \\
& $(2 / 5,1 / 2,2 / 3)$ & $(3 / 2,2,5 / 2)$ & $(1,1,1)$ & $(2 / 5,1 / 2,2 / 3)$ \\
\hline Supplier 4 & $(2 / 9,1 / 4,2 / 7)$ & $(2 / 5,1 / 2,2 / 3)$ & $(2 / 5,1 / 2,2 / 3)$ & $(1,1,1)$ \\
& $(2 / 5,1 / 2,2 / 3)$ & $(2 / 3,1,3 / 2)$ & $(2 / 5,1 / 2,2 / 3)$ & $(1,1,1)$ \\
& $(2 / 5,1 / 2,2 / 3)$ & $(2 / 3,1,3 / 2)$ & $(3 / 2,2,5 / 2)$ & $(1,1,1)$ \\
\hline
\end{tabular}

Table 4: The alternatives fuzzy pair-wise comparison matrix with respect to criteria Delivery in kth period $(k=1,2,3)$

\begin{tabular}{|l|l|l|l|l|}
\hline Delivery & Supplier 1 & Supplier 2 & Supplier 3 & Supplier 4 \\
\hline \multirow{3}{*}{ Supplier 1 } & $(1,1,1)$ & $(2 / 3,1,3 / 2)$ & $(2 / 3,1,3 / 2)$ & $(2 / 3,1,3 / 2)$ \\
& $(1,1,1)$ & $(2 / 9,1 / 4,2 / 7)$ & $(2 / 3,1,3 / 2)$ & $(2 / 5,1 / 2,2 / 3)$ \\
& $(1,1,1)$ & $(2 / 3,1,3 / 2)$ & $(1,1,1)$ & $(2 / 5,1 / 2,2 / 3)$ \\
\hline \multirow{3}{*}{ Supplier 2 } & $(2 / 3,1,3 / 2)$ & $(1,1,1)$ & $(3 / 2,2,5 / 2)$ & $(3 / 2,2,5 / 2)$ \\
& $(7 / 2,4,9 / 2)$ & $(1,1,1)$ & $(3 / 2,2,5 / 2)$ & $(3 / 2,2,5 / 2)$ \\
& $(2 / 3,1,3 / 2)$ & $(1,1,1)$ & $(2 / 5,1 / 2,2 / 3)$ & $(2 / 3,1,3 / 2)$ \\
\hline \multirow{3}{*}{ Supplier 3 } & $(2 / 3,1,3 / 2)$ & $(2 / 5,1 / 2,2 / 3)$ & $(1,1,1)$ & $(3 / 2,2,5 / 2)$ \\
& $(2 / 3,1,3 / 2)$ & $(2 / 5,1 / 2,2 / 3)$ & $(1,1,1)$ & $(2 / 3,1,3 / 2)$ \\
& $(1,1,1)$ & $(3 / 2,2,5 / 2)$ & $(1,1,1)$ & $(2 / 5,1 / 2,2 / 3)$ \\
\hline & $(2 / 5,1 / 2,2 / 3)$ & $(2 / 5,1 / 2,2 / 3)$ & $(2 / 5,1 / 2,2 / 3)$ & $(1,1,1)$ \\
Supplier 4 & $(3 / 2,2,5 / 2)$ & $(2 / 5,1 / 2,3 / 2)$ & $(2 / 3,1,3 / 2)$ & $(1,1,1)$ \\
& $(3 / 2,2,5 / 2)$ & $(2 / 3,1,3 / 2)$ & $(3 / 2,2,5 / 2)$ & $(1,1,1)$ \\
\hline
\end{tabular}


Table 5: The alternatives fuzzy pair-wise comparison matrix with respect to criteria Cost in kth period $(k=1,2,3)$

\begin{tabular}{|l|l|l|l|l|}
\hline Cost & Supplier 1 & Supplier 2 & Supplier 3 & Supplier 4 \\
\hline Supplier 1 & $(1,1,1)$ & $(3 / 2,2,5 / 2)$ & $(2 / 3,1,3 / 2)$ & $(5 / 2,3,7 / 2)$ \\
& $(1,1,1)$ & $(3 / 2,2,5 / 2)$ & $(3 / 2,2,5 / 2)$ & $(2 / 3,1,3 / 2)$ \\
& $(1,1,1)$ & $(3 / 2,2,5 / 2)$ & $(3 / 2,2,5 / 2)$ & $(2 / 3,1,3 / 2)$ \\
\hline Supplier 2 & $(2 / 5,1 / 2,2 / 3)$ & $(1,1,1)$ & $(2 / 3,1,3 / 2)$ & $(3 / 2,2,5 / 2)$ \\
& $(2 / 5,1 / 2,2 / 3)$ & $(1,1,1)$ & $(1,1,1)$ & $(3 / 2,2,5 / 2)$ \\
& $(2 / 5,1 / 2,2 / 3)$ & $(1,1,1)$ & $(1,1,1)$ & $(3 / 2,2,5 / 2)$ \\
\hline Supplier 3 & $(2 / 3,1,3 / 2)$ & $(2 / 3,1,3 / 2)$ & $(1,1,1)$ & $(3 / 2,2,5 / 2)$ \\
& $(2 / 5,1 / 2,2 / 3)$ & $(1,1,1)$ & $(1,1,1)$ & $(2 / 5,1 / 2,2 / 3)$ \\
& $(2 / 5,1 / 2,2 / 3)$ & $(1,1,1)$ & $(1,1,1)$ & $(2 / 5,1 / 2,2 / 3)$ \\
\hline Supplier 4 & $(2 / 7,1 / 3,2 / 5)$ & $(2 / 5,1 / 2,2 / 3)$ & $(2 / 5,1 / 2,2 / 3)$ & $(1,1,1)$ \\
& $(2 / 3,1,3 / 2)$ & $(2 / 5,1 / 2,2 / 3)$ & $(2 / 5,1 / 2,2 / 3)$ & $(1,1,1)$ \\
& $(2 / 3,1,3 / 2)$ & $(2 / 5,1 / 2,2 / 3)$ & $(3 / 2,2,5 / 2)$ & $(1,1,1)$ \\
\hline
\end{tabular}

Table 6: The alternatives fuzzy pair-wise comparison matrix with respect to criteria Flexibility in Service in kth period $(k=1,2,3)$

\begin{tabular}{|l|l|l|l|l|}
\hline $\begin{array}{l}\text { Flexibility in } \\
\text { Service }\end{array}$ & Supplier 1 & Supplier 2 & Supplier 3 & Supplier 4 \\
\hline Supplier 1 & $(1,1,1)$ & $(3 / 2,2,5 / 2)$ & $(3 / 2,2,5 / 2)$ & $(3 / 2,2,5 / 2)$ \\
& $(1,1,1)$ & $(2 / 9,1 / 4,2 / 7)$ & $(2 / 3,1,3 / 2)$ & $(2 / 5,1 / 2,2 / 3)$ \\
& $(1,1,1)$ & $(2 / 3,1,3 / 2)$ & $(2 / 3,1,3 / 2)$ & $(2 / 5,1 / 2,2 / 3)$ \\
\hline Supplier 2 & $(2 / 5,1 / 2,2 / 3)$ & $(1,1,1)$ & $(3 / 2,2,5 / 2)$ & $(3 / 2,2,5 / 2)$ \\
& $(7 / 2,4,9 / 2)$ & $(1,1,1)$ & $(3 / 2,2,5 / 2)$ & $(3 / 2,2,5 / 2)$ \\
& $(2 / 3,1,3 / 2)$ & $(1,1,1)$ & $(2 / 3,1,3 / 2)$ & $(2 / 5,1 / 2,2 / 3)$ \\
\hline Supplier 3 & $(2 / 5,1 / 2,2 / 3)$ & $(2 / 5,1 / 2,2 / 3)$ & $(1,1,1)$ & $(2 / 3,1,3 / 2)$ \\
& $(2 / 3,1,3 / 2)$ & $(2 / 5,1 / 2,2 / 3)$ & $(1,1,1)$ & $(2 / 3,1,3 / 2)$ \\
& $(3 / 2,1,3 / 2)$ & $(2 / 3,1,3 / 2)$ & $(1,1,1)$ & $(2 / 5,1 / 2,2 / 3)$ \\
\hline Supplier 4 & $(2 / 5,1 / 2,2 / 3)$ & $(2 / 5,1 / 2,2 / 3)$ & $(2 / 3,1,3 / 2)$ & $(1,1,1)$ \\
& $(3 / 2,2,5 / 2)$ & $(2 / 5,1 / 2,2 / 3)$ & $(2 / 3,1,3 / 2)$ & $(1,1,1)$ \\
& $(3 / 2,2,5 / 2)$ & $(3 / 2,3,5 / 2)$ & $(3 / 2,2,5 / 2)$ & $(1,1,1)$ \\
\hline
\end{tabular}

For identifying the computation procedures, the pair-wise judgments from the Table 3 for the period 3 are evaluated as follows:

\begin{tabular}{|l|l|l|l|l|}
\hline Quality & Supplier 1 & Supplier 2 & Supplier 3 & Supplier 4 \\
\hline Supplier 1 & $(1,1,1)$ & $(2 / 3,1,3 / 2)$ & $(3 / 2,2,5 / 2)$ & $(3 / 2,2,5 / 2)$ \\
\hline Supplier 2 & $(2 / 3,1,3 / 2)$ & $(1,1,1)$ & $(2 / 5,1 / 2,2 / 3)$ & $(2 / 3,1,3 / 2)$ \\
\hline Supplier 3 & $(2 / 5,1 / 2,2 / 3)$ & $(3 / 2,2,5 / 2)$ & $(1,1,1)$ & $(2 / 5,1 / 2,2 / 3)$ \\
\hline Supplier 4 & $(2 / 5,1 / 2,2 / 3)$ & $(2 / 3,1,3 / 2)$ & $(3 / 2,2,5 / 2)$ & $(1,1,1)$ \\
\hline
\end{tabular}




$$
\begin{aligned}
& \text { Supplier }_{1 Q}=(4.667,6,7.5) \otimes(1 / 20.00,1 / 18.00,1 / 14.267)=(0.2333,0.333,0.526) \\
& \text { Supplier }_{2 Q}=(2.733,3.5,4.667) \otimes(1 / 20.00,1 / 18.00,1 / 14.267)=(0.137,0.194,0.327) \\
& \text { Supplier }_{3 Q}=(3.30,4.0,4.833) \otimes(1 / 20.00,1 / 18.00,1 / 14.267)=(0.165,0.222,0.339) \\
& \text { Supplier }_{4 Q}=(3.567,4.5,4.667) \otimes(1 / 20.00,1 / 18.00,1 / 14.267)=(0.178,0.250,0.327)
\end{aligned}
$$

After determining these results, these fuzzy values are compared by using Eq. (7)

$V\left(\right.$ Supplier $_{1 Q} \geq$ Supplier $\left._{2 Q}\right)=1, V\left(\right.$ Supplier $_{1 Q} \geq$ Supplier $\left._{3 Q}\right)=1, V\left(\right.$ Supplier $_{1 Q} \geq$ Supplier $\left._{4 Q}\right)=1$

$V\left(\right.$ Supplier $_{2 Q} \geq$ Supplier $\left._{1 Q}\right)=0.402, V\left(\right.$ Supplier $_{2 Q} \geq$ Supplier $\left._{3 Q}\right)=0.853$, V $_{\text {Supplier }}$ S $_{2 Q} \geq$ Supplier $\left._{4 Q}\right)=0.727$

$V\left(\right.$ Supplier $_{3 Q} \geq$ Supplier $\left._{1 Q}\right)=0.484, V\left(\right.$ Supplier $_{3 Q} \geq$ Supplier $\left._{2 Q}\right)=1, V\left(\right.$ Supplier $_{3 Q} \geq$ Supplier $\left._{4 Q}\right)=0.851$

$V\left(\right.$ Supplier $_{4 Q} \geq$ Supplier $\left._{1 Q}\right)=0.528, V\left(\right.$ Supplier $_{4 Q} \geq$ Supplier $\left._{2 Q}\right)=1, V\left(\right.$ Supplier $_{4 Q} \geq$ Supplier $\left._{3 Q}\right)=1$

Then priority weights are calculated by using Eq. (8):

$$
\begin{aligned}
& d^{\prime}\left(\text { Supplier }_{1 Q}\right)=\min (1,1,1)=1 \\
& d^{\prime}\left(\text { Supplier }_{2 Q}\right)=\min (0.402,0.853,0.727)=0.402 \\
& d^{\prime}\left(\text { Supplier }_{3 Q}\right)=\min (0.484,1,0.851)=1 \\
& d^{\prime}\left(\text { Supplier }_{4 Q}\right)=\min (0.528,1,1)=0.528
\end{aligned}
$$

Therefore, the weight vector from Table 3 for the period 3 is calculated as

$$
W_{Q}^{\text {Supplier }}=(1,0.402,1,0.528)
$$

After the normalization of these values priority weights with respect to criteria Quality are calculated as

$$
W_{Q}^{\text {Supplier }}=(0.414,0.167,0.200,0.219)
$$

The same systematic approach is considered for the other evaluations, and priority weights are expressed correspondingly in Tables 7-10 as follows. Table 11 represents the priority weights of the four suppliers in all three periods and is obtained by multiplying the priority weights of criteria to the suppliers' weights with respect to all criteria in each period respectively.

\section{Discussion of Result}

As we can see in Figure 3, the priority of quality improvement is important for every supplier for all periods. We can also observe from the Table 7 that the cost is more important than the delivery in all three periods. From Figure 4, we know the trend of supplier's priority; Supplier 1 is the most suitable supplier in all three periods. But there is some difference in selecting all other suppliers in three periods.

Table 7: The priorities weights of Criteria in period 1-3

\begin{tabular}{|l|l|l|l|}
\hline Criteria & Period1 & Period2 & Period3 \\
\hline Quality & 0.42 & 0.47 & 0.43 \\
\hline Delivery & 0.18 & 0.15 & 0.23 \\
\hline Cost & 0.26 & 0.25 & 0.29 \\
\hline Flexibility in Service & 0.14 & 0.14 & 0.05 \\
\hline
\end{tabular}


Table 8: The priorities weights of suppliers with respect to all criteria in period 1

\begin{tabular}{|l|l|l|l|l|}
\hline & Quality & Delivery & Cost & $\begin{array}{l}\text { Flexibility in } \\
\text { Service }\end{array}$ \\
\hline Supplier 1 & 0.61 & 0.27 & 0.41 & 0.54 \\
\hline Supplier 2 & 0.06 & 0.43 & 0.21 & 0.34 \\
\hline Supplier 3 & 0.21 & 0.30 & 0.26 & 0.06 \\
\hline Supplier 4 & 0.12 & 0.00 & 0.12 & 0.06 \\
\hline
\end{tabular}

Table 9: The priorities weights of suppliers with respect to all criteria in period 2

\begin{tabular}{|l|l|l|l|l|}
\hline & Quality & Delivery & Cost & $\begin{array}{l}\text { Flexibility in } \\
\text { Service }\end{array}$ \\
\hline Supplier 1 & 0.48 & 0.31 & 0.38 & 0.00 \\
\hline Supplier 2 & 0.17 & 0.69 & 0.27 & 0.85 \\
\hline Supplier 3 & 0.35 & 0.00 & 0.00 & 0.00 \\
\hline Supplier 4 & 0.00 & 0.00 & 0.35 & 0.15 \\
\hline
\end{tabular}

Table 10: The priorities weights of suppliers with respect to all criteria in period 3

\begin{tabular}{|l|l|l|l|l|}
\hline & Quality & Delivery & Cost & Flexibility in Service \\
\hline Supplier 1 & 0.414 & 0.14 & 0.38 & 0.17 \\
\hline Supplier 2 & 0.167 & 0.18 & 0.27 & 0.17 \\
\hline Supplier 3 & 0.200 & 0.26 & 0.00 & 0.17 \\
\hline Supplier 4 & 0.219 & 0.42 & 0.00 & 0.51 \\
\hline
\end{tabular}

Table 11: The priorities weights of suppliers in period 1-3

\begin{tabular}{|l|l|l|l|}
\hline Suppliers & Period1 & Period2 & Period3 \\
\hline $\mathbf{1}$ & 0.4870 & 0.367 & 0.329 \\
\hline $\mathbf{2}$ & 0.2048 & 0.370 & 0.200 \\
\hline $\mathbf{3}$ & 0.2182 & 0.165 & 0.195 \\
\hline $\mathbf{4}$ & 0.0900 & 0.109 & 0.216 \\
\hline
\end{tabular}




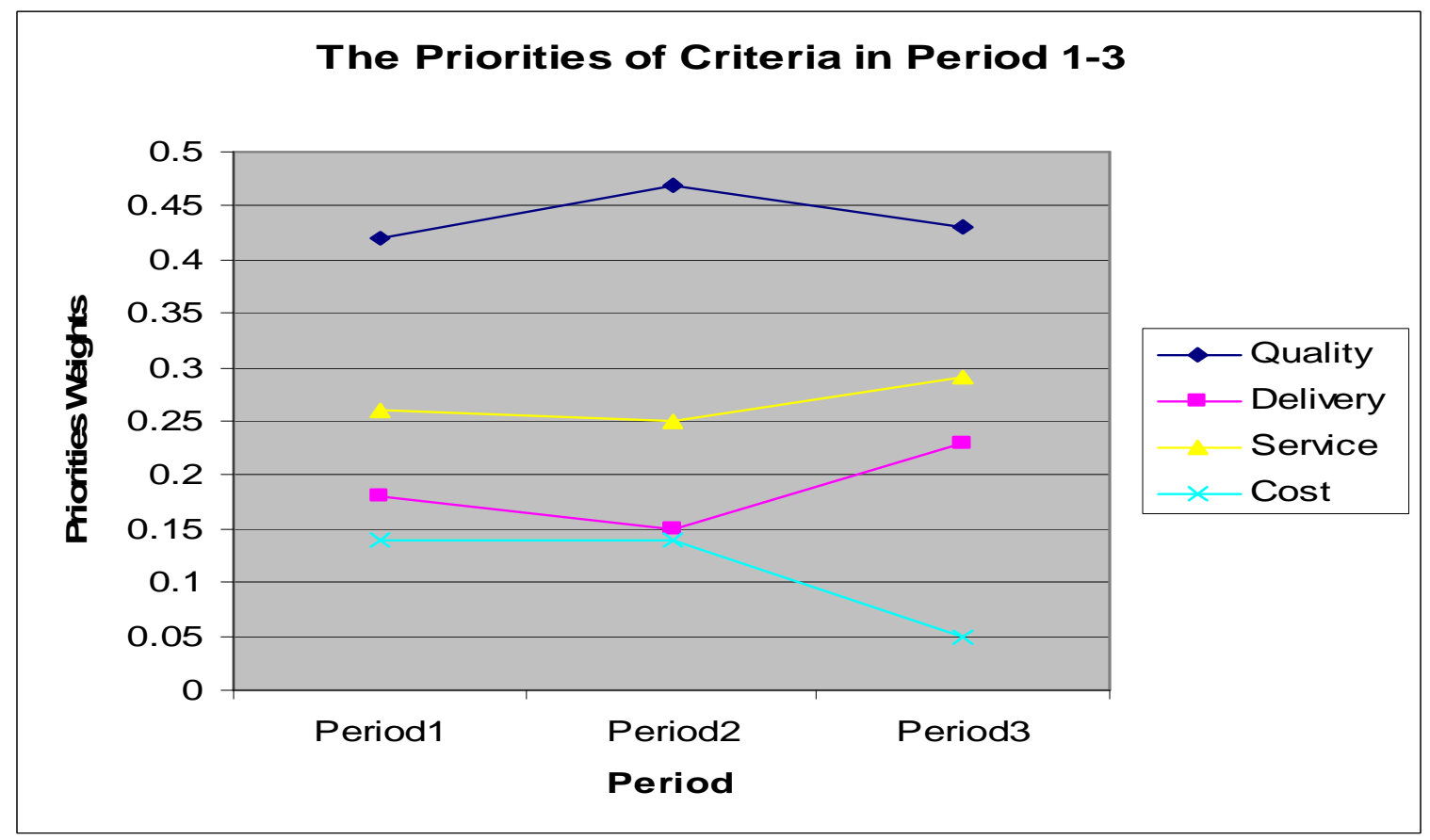

Figure 3: Priorities of Criteria in period 1-3

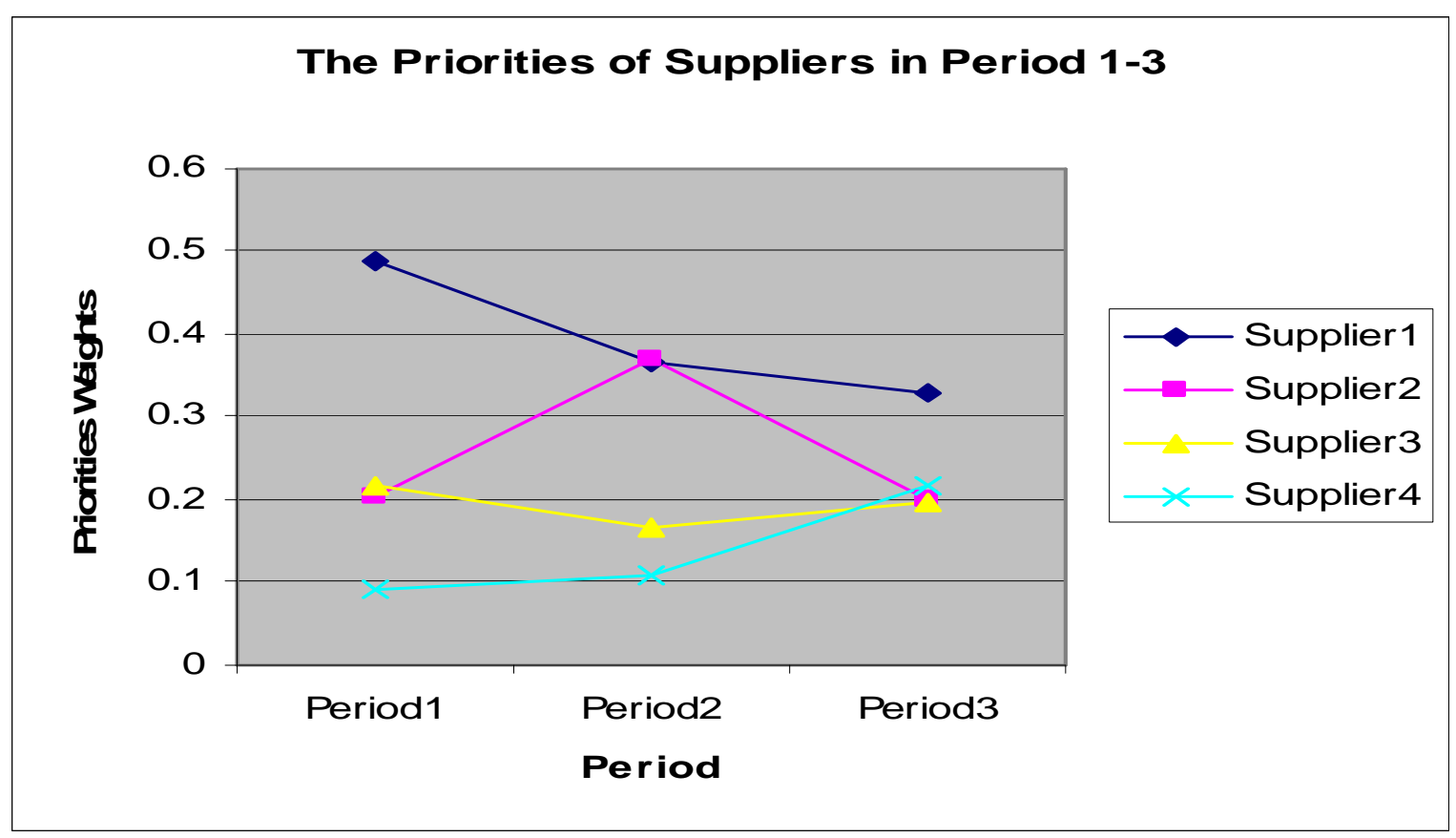

Figure 4: Priorities of Suppliers in period 1-3 


\section{Conclusions}

Customarily in global supply chain management, companies have to select suitable suppliers over a long period of time. Under dynamic business environments, the attributes and weights may change, becoming not necessarily crisp, but rather fuzzy in nature. Traditional multiple attribute decision-making methods may not solve the long-term performance measurement problems in fuzzy environments. This paper proposes a dynamic approach based on Fuzzy AHP for supplier selection problems that can help us to reach an effective decision. By this way we can deal with the uncertainty and vagueness in the decision process. In future work, we will try to extend Fuzzy AHP method to Intuistionistic Fuzzy AHP method to select the suppliers.

\section{REFERENCES}

Barbarosoglu G., \& Yazgac, T., (1997). An application of the analytic hierarchy process to the supplier selection problem. Production and Inventory Management Journal, 38(1), 14-21.

Bellman, R.E., \& Zadeh, L.A. (1970). Decision making in a fuzzy environment. Management Sciences, $17,141-164$.

Benyoucef Morad and Canbolat Mustafa (2007). Fuzzy AHP-based supplier selection in e-procurement. International Journal of Services and Operations Management, 3(2), 172 -192.

Buckley J.J., Feuring T., \& Hayashi Y., (2001). Fuzzy hierarchical analysis revisited. European Journal of Operational Research, 129, 48-64.

Chan, F. T. S. and N. Kumar. (2007) "Global supplier development considering risk factors using fuzzy extended AHP-based approach,” Omega, 35 (4), 417--431.

Chang D. (1996). Application of the extent analysis method on fuzzy AHP. European Journal of Operational Research, 95, 649-655.

Chen, Chen-Tung, Ching-Torng Lin, and Sue-Fn Huang. (2006) A fuzzy approach for supplier evaluation and selection in supply chain management, International Journal of Production Economics, 102 (2), 289-301.

Degraeve, Z., Labro, E., \& Roodhooft, F., (2000). An evaluation of vendor selection models from a total cost of ownership perspective. European Journal of Operational Research, 125, 34-58.

Dickson, G., (1966). An analysis of vendor selection systems and decisions. Journal of Purchasing, 2(1), 5-17.

Hartley, J.L., \& Choi, T.Y., (1996). Supplier development: Customer as a catalyst of process change. Business Horizons, 39(4), 37-40.

Heizer, J.\& Render, B. (2001). Operations Management. Prentice-Hall, 431-457.

Kahraman C., Cebeci, U., Ruan, D., (2004) Multi-attribute comparison of catering service companies using fuzzy AHP: the case of Turkey. International Journal of Production Economics, 87, 171-184.

Leung, L.C., \& Cao, D., (2000). Theory and Methodology, on consistency and ranking of alternatives in fuzzy AHP. European Journal of Operational Research, 124, 102-113. 
Mandal, A., \& Deshmukh, S.G., (1994). Vendor selection using interpretive structural modeling. International Journal of Operations \& Production Management, 14 (6), 52-59.

Motwani, J., Youssef, M., Kathawala, Y., \& Futch, E. (1999). Supplier selection in developing countries: a model development. Integrated Manufacturing System, 10 (3), 154-161.

Min, H., (1994). International Supplier Selection. International Journal of Physical Distribution \& Logistics Management, 24(5), 24-33.

Noci, G., \& Toletti, G., (2000). Selecting quality-based programmes in small firms: A comparison between the fuzzy linguistic approach and the analytic hierarchy process. International Journal of Production Economics, 67, 113-133.

Oliveira, R.C., \& Lourenço, J.C., (2002). A multicriteria model for assigning new orders to service suppliers. European Journal of Operational Research, 139(2), 390-399.

Saaty, T.L. (1980). The Analytical Hierarchy Process. McGraw-Hill, New York, NY.

Weber, C. A., Current, J. R., \& Desai, A., (2000). An optimization approach to determining the number of vendors to employ. Supply Chain Management: An International Journal, 2(5), 90-98.

Yan, H., Yu, Z., \& Cheng, T.C.E., (2003). A Strategic model for supply chain design with logical constratints: Formulation and solution. Computers \& Operations Research, 30(14), 2135-2155.

Youssef, M.A., Zairi, M., \& Mohanty, B., (1996). Supplier selection in an advanced manufacturing technology environment: an optimization model. Benchmarking for Quality Management \& Technology, 3(4), 60-72.

Zaim, S., Sevkli, M. and Tarim, M., (2003). "Fuzzy Analytic Hierarchy Based Approach for Supplier Selection", Journal of Euromarketing, 12( 3/4), pp. 147-176.

Zimmermann, H.J., (1991). Fuzzy Set Theory and Its Applications. Kluwer Academic Publishers, Dordrecht. 